\title{
ANALYSIS OF S-S SHORT CYLINDRICAL SHELLS UNDER INTERNAL HYDROSTATIC PRESSURE USING POLYNOMIAL SERIES SHAPE FUNCTION
}

\author{
Agbo S.I ${ }^{1}$, Dike B.U², Anyanwu T. $\mathbf{U}^{3}$, Onyechere I.C ${ }^{4}$ \\ ${ }^{1}$ Lecturer, Civil Engineering Department, Federal Unitech Owerri, Imo State, Nigeria. \\ ${ }^{2}$ Associate Professor Civil Engineering Department, Federal Unitech Owerri, Imo State, Nigeria. \\ ${ }^{3}$ Lecturer, Civil Engineering Department, Federal Unitech Owerri, Imo State, Nigeria. \\ ${ }^{4}$ Lecturer,Civil Engineering Department, Federal Unitech Owerri, Imo State, Nigeria.
}

\begin{abstract}
A new approach to the analysis of S-S short cylindrical shells subject to internal hydrostatic pressure is presented. Short cylindrical shells with both ends simply supported $(S-S)$ loaded with axisymmetric internal hydrostatic pressure was considered. By satisfying the boundary conditions of S-S short cylindrical shell in the general polynomial series shape function, a particular shape function for the shell was obtained. This shape function was substituted into the total potential energy functional of conservation of work principle, and by minimizing the functional; the unknown coefficient of the particular polynomial shape function was obtained. Bending moments, shear forces and deflections of the shell were determined, and used in plotting graphs for a range of aspect ratios, $1 \leq L / r \leq 4$. Stresses and deflections at various points of the shell were determined for different cases. Considering case one, with aspect ratio 1, maximum values of deflection, rotation, bending moment and shear force were $9.6639 * 10^{-4} \mathrm{~m},-3.29878 * 10^{-3}$ radians, $343.07309 \mathrm{KNm}$ and $-1786.839 \mathrm{KN}$ respectively. Thus we observed that the stresses and strains along the $S-S$ short cylindrical reservoir vary inversely as the aspect ratio.
\end{abstract}

Key Words: Analysis, Boundary condition, Conservation of work principle, Hydrostatic pressure, Polynomial series, Shape function, Short cylindrical shell.

\section{INTRODUCTION}

Thin shells as structural elements occupy a leadership position in engineering and especially in civil engineering, since they can be used in the construction of large liquid storage structures, large span roofs, domes, folded plates and so on.

Vlasov [1], by ignoring the effects of longitudinal bending moment, shear forces and torques arrived at the semimoment theory, which is found to give acceptable results in the analysis of cylindrical shells. Timoshenko and Woinowsky-Krieger [2] experimentally verified on cylindrical shell whose ratio of length to radius (aspect ratio) ranges from 1 to 4. Pasternak [3] showed that when the load on a cylindrical shell is axisymmetric, the stresses and strains are functions of only one variable along the axis of the cylinder.

Cylindrical shell tanks are widely used in the construction of strategic water or oil reservoir all over the world Yukun et al [4] In order to lower the cost, and to make the management easier, the volume of such tanks tends to be larger, thus short cylindrical shell. Osadebe and Adamou [5] studied Static Analysis of Cylindrical shell under hydrostatic and Ring forces using initial value method. Ventsel and Krauthammer [6] studied short cylindrical shell using the Krylov's function but did not consider the case of axisymmetrically loaded with internal hydrostatic pressure.
Ezeh et al, 2014 [7] studied Static Analysis of C-S short cylindrical shell under internal liquid pressure but did not consider the case of S-S boundary condition.

The larger the tanks are built, the higher the hydrostatic pressure due to the liquid it contained and thus the higher the risk of failure. Failure of this structure is catastrophic as it involves huge economic loss, risk to life and unimaginable environmental degradation. Therefore, more attention should be given to a thorough and comprehensive structural analysis of such structures, which will lead to safe design and construction. S-S short cylindrical shell is a type of short cylindrical shell reservoir that has both ends simply supported. This can be obtained in the case of reservoir made without fixing the base permanently on the foundation and thus it is free to rotate at both ends. This is a typical make shift reservoir that can be dismantled after usage. Examples of this are large cylindrical shell reservoirs used as hydraulic structure for water storage.

The objective of this study is to establish an analysis of S-S short cylindrical shell that can be utilized in the design of cylindrical shell reservoir tank and to show the distribution of stress and strain on the S-S shell reservoir under working load. The magnitudes and locations of critical values of stresses and strains along the height of the cylindrical shell tanks were indicated and recorded for the purpose of design. 


\section{GOVERNING DIFFERENTIAL EQUATION OF A} CYLINDRICAL SHELL.

Considering an S-S short cylindrical shell with its dimension $\mathrm{L}, \mathrm{t}$ and $\mathrm{r}$, as shown in Fig. 1 which is subjected to axisymmetric internal hydrostatic pressure.

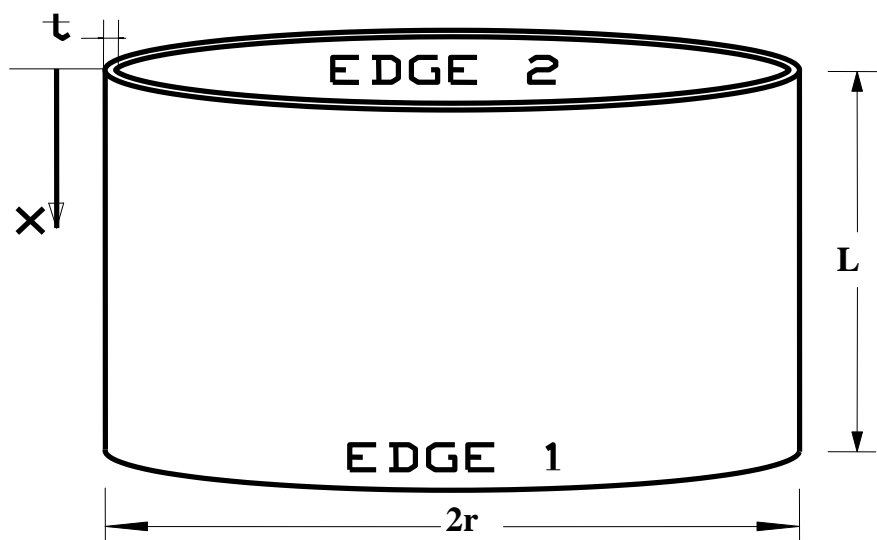

Figure 1: A typical S-S (Simply supported at both edges) short cylindrical shell tank showing the dimensions.

According to Ezeh et al, 2014 [7], the condition for shortness for an unstiffened cylindrical shell is $\mathrm{L} / \mathrm{r}<5$, where $\mathrm{L} / \mathrm{r}$ is the aspect ratio.

The governing equation of a cylindrical shell according to the semi-moment theory as used by Timoshenko et al [2]; Ugural [8]; Ventsel and Krauthammer [6] is as stated in equation (1).

$\frac{d^{4} w}{d x^{4}}+4 \beta^{4} w=\frac{\gamma}{D} \mathrm{x}$

Where

$\beta^{4}=\frac{3\left(1-v^{2}\right)}{r^{2} t^{2}}$

$\gamma=$ Unite weight of the liquid.

Equation (1) is due to Pasternak [3] and is only applicable to cylindrical shell subject to axisymmetric loading.

Ezeh et al, 2014 [7] gave the general polynomial series shape function for short cylindrical shell as:

$$
\mathrm{w}=k_{0}+k_{1} R+k_{2} R^{2}+k_{3} R^{3}+k R^{5}
$$

Where, $k_{0}=a_{0} c ; k_{1}=a_{1} c ; k_{2}=a_{2} c ; k_{3}=a_{3} c ; k_{5}=\Phi b$

\section{SHAPE FUNCTION FOR S-S SHORT}

\section{CYLINDRICAL SHELL.}

The S-S short cylindrical shell has the following boundary conditions:
$w_{0}=w(R=0)=0$

$M_{0}=\frac{d^{2} w}{d R^{2}}(R=0)=0$

$w_{(1)}=w(R=1)=0$

$M_{(1)}=\frac{d^{2} W}{d R^{2}}(R=1)=0$

Substituting the boundary conditions in equations (5), (6), (7) and (8) into equation (3) and solving the resulting equations gave :

$w=A\left(\frac{7}{a} R-\frac{10}{a} R^{2}+R^{5}\right)=A f_{i}$

Equation (9) is the shape function for S-S short cylindrical shell under internal hydrostatic pressure.

\section{THE CONSERVATION}

OF

\section{WORK PRINCIPLE.}

The conservation of work principle used in the formulation of the solution for the C-F short cylindrical shell was obtained from Ibearugbulem et al [9].

$$
\int_{0}^{L}\left(\frac{d^{4} w}{d R^{4}}\right) w d R+\lambda \int_{0}^{L} w^{2} d R-\int_{0}^{L} \Phi w R d=0
$$

\section{CONSERVATION OF WORK PRINCIPLE} SOLUTION FOR S-S SHORT CYLINDRICAL SHELL.

The shape function for $\mathrm{S}-\mathrm{S}$ short cylindrical shell is given by equation (9) as:

$w=A\left(\frac{7}{3} R-\frac{10}{3} R^{a}+R^{5}\right)$

Using the conservation of work principle solution as stated in equation (10) as follows:

$\int_{0}^{L}\left(\frac{d^{4} w}{d R^{4}}\right) w d R+\lambda \int_{0}^{L} w^{2} d R-\int_{0}^{L} \Phi w R d R=0$

Using equation (9), the following values were obtained:

$$
\begin{aligned}
& \frac{\mathrm{d}^{4} \mathrm{w}}{\mathrm{d} \mathrm{R}^{4}} \mathrm{w}=120 A^{2}\left(\frac{7}{\mathrm{a}} R^{2}-\frac{10}{\mathrm{a}} R^{4}+R^{6}\right) \\
& w^{2}=A^{2}\left(\frac{49}{9} R^{2}-\frac{140}{9} R^{4}+\frac{142}{9} R^{6}-\frac{20}{3} R^{9}+R^{10}\right) \\
& w R=A\left(\frac{7}{3} R^{2}-\frac{10}{3} R^{4}+R^{6}\right)
\end{aligned}
$$

Integrating equations (11), (12) and (13) with respect to $\mathrm{R}$ in a closed domain respectively gave the following: 
$\int_{0}^{1}\left(\frac{\mathrm{d}^{4} \mathrm{w}}{\mathrm{dR}^{4}}\right) \mathrm{w} d R=120 A^{2}\left(\frac{7}{9}-\frac{10}{15}+\frac{1}{7}\right)=30.476192 A^{2}$

$\int_{0}^{1}(w)^{2} d R=A^{2}\left(\frac{49}{27}-\frac{140}{45}+\frac{142}{63}-\frac{20}{27}+\frac{1}{11}\right)=0.30784 A^{2}$

$\int_{0}^{1}(w R) d R=A\left(\frac{7}{9}-\frac{10}{15}+\frac{1}{7}\right)=0.253968 A$

Substituting equations (14), (15) and (16) into the conservation of work principle equation (10) gave:

$30.476192 A^{2}+0.30784 A^{2} \lambda-0.253968 A \Phi=0$

Making A the subject of equation (17) gave:

$A=\frac{0.253968 \Phi}{30.47619+0.30784 \lambda}$

Recalling the following:

$\Phi=\frac{y L^{5}}{\mathbb{D}}$

$\lambda=\frac{12 L^{4}\left(1-v^{2}\right)}{r^{2} t^{2}}$

Substituting for $\Phi, \lambda$, and simplifying further, we have:

$A=\frac{0.825 y L^{5} r^{2}}{99.0 r^{2} D+E t L^{4}}$

Substituting equation (19) into equation (9) gave:

$w=\frac{0.825 \gamma L^{5} \mathrm{r}^{2}}{99.0 \mathrm{r}^{2} D+E t L^{4}}\left(\frac{7}{3} R-\frac{10}{3} R^{a}+R^{5}\right)$

Equation (20) is the shape function for an S-S short cylindrical shell using polynomial series in the conservation of work principle.

6. FOR AN S-S SHORT CYLINDRICAL SHELL,

\section{THE DEFORMATIONS AND STRESSES}

\section{EQUATIONS ARE:}

\subsection{Deflection (W).}

The deflection is obtained by substituting the numerical values of all the parameters in the shape function shown.

$w=\frac{0.825 \gamma L^{5} \mathrm{r}^{2}}{99.0 \mathrm{r}^{2} D+E t L^{4}}\left(\frac{7}{3} R-\frac{10}{3} R^{3}+R^{5}\right)$

\subsection{SLOPE (ROTATION) ( $\theta)$.}

Differentiating equation (21) with respect to $\mathrm{R}$ gave the slope.

$\theta=\frac{d w}{d R}=\frac{0.825 \gamma L^{5} \mathrm{r}^{2}}{99.0 \mathrm{r}^{2} D+E t L^{4}}\left(\frac{7}{3}-10 R^{2}+5 R^{4}\right)$

\subsection{Bending Moment (M)}

Differentiating equation (22) with respect to $\mathrm{R}$ and multiplying with the negative value of the flexural rigidity $\mathrm{D}$ gave the bending moment.

$M=-D\left(\frac{d^{2} w}{d R^{2}}\right)=-D\left[\frac{0.825 \gamma L^{5} \mathrm{r}^{2}}{99.0 \mathrm{r}^{2} D+E t L^{4}}\right]\left(20 R^{3}-20 R\right)$

\subsection{Shear force $(Q)$}

Differentiating equation (23) with respect to $\mathrm{R}$ gave the shear force.

$Q=-D\left(\frac{d^{3} w}{d R^{3}}\right)=-D\left[\frac{0.825 \gamma L^{5} \mathrm{r}^{2}}{99.0 \mathrm{r}^{2} D+E t L^{4}}\right]\left(60 R^{2}-20\right)$

\section{NUMERICAL STUDIES}

The stresses and strains at various points of $\mathrm{S}-\mathrm{S}$ short cylindrical shells were determined for values of aspect ratios ranging from 1 to 4 . The equations of the deformations and stresses of S-S short cylindrical shells are presented. The numerical values of the following parameters E, D, L, t, r and $\gamma$ are substituted accordingly into the formulated solutions.

\section{RESULTS AND DISCUSSION}

The graphs of each of the deflections, slopes, bending moments and shear forces for S-S short cylindrical shell of cases 1 to 4 were plotted together against the height of the tank and presented as follows:

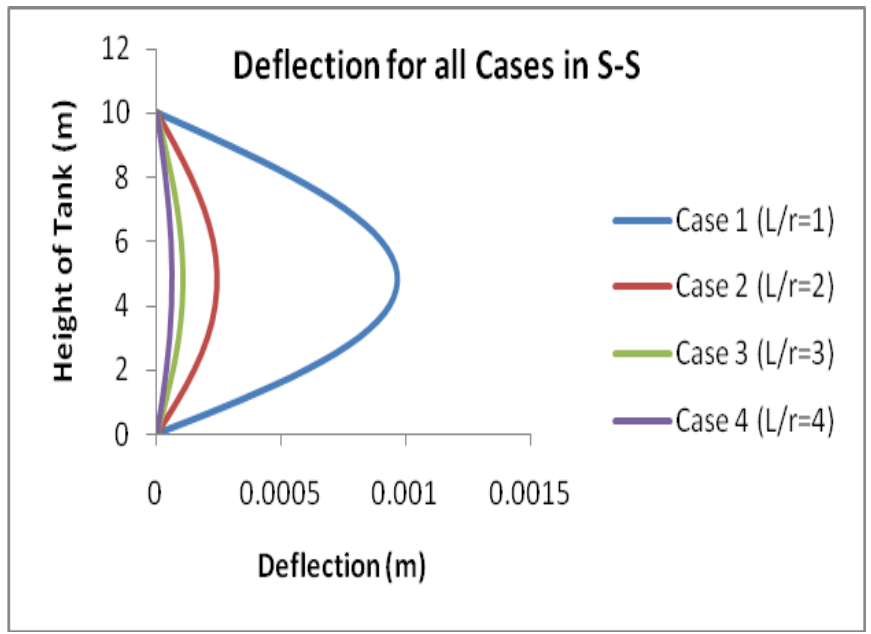

Figure 2: Deflection curves for S-S short cylindrical shells of aspect ratios 1 to 4 . 


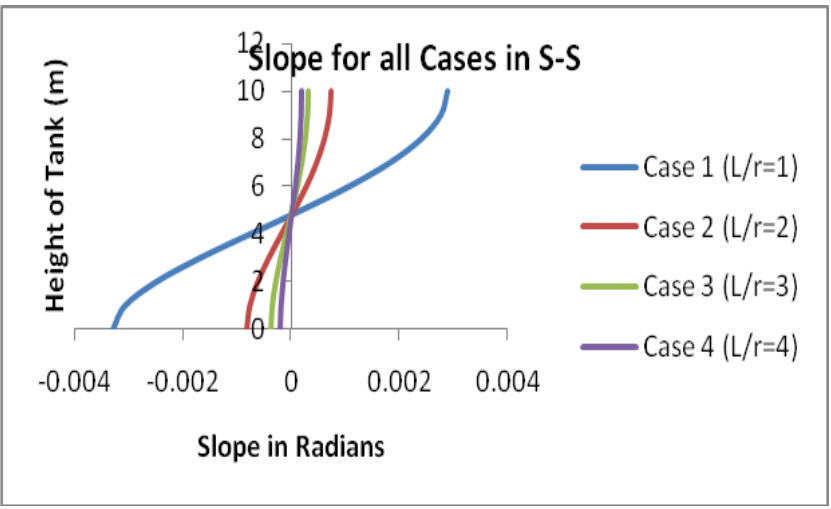

Figure 3: Rotation curves for S-S short cylindrical shells of aspect ratios 1 to 4 .

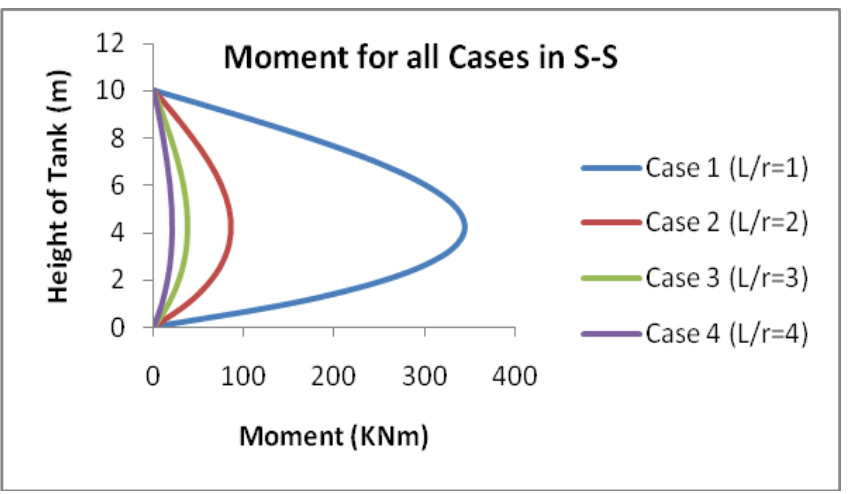

Figure 4: Bending moment diagrams for S-S short cylindrical shells of aspect ratios 1 to 4 .

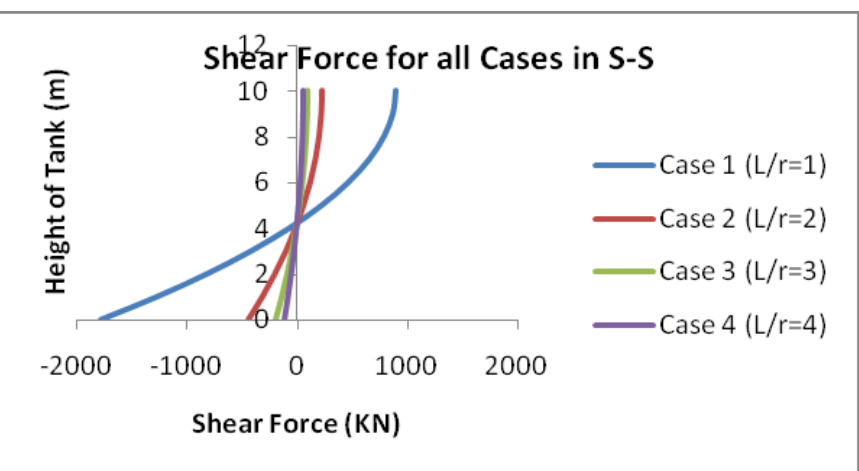

Figure 5: Shear force diagrams for S-S short cylindrical shells of aspect ratios 1 to 4 .

Table 1: Maximum values of deflections, rotations, bending moments and shear forces for S-S short cylindrical shell.

\begin{tabular}{|c|l|l|l|l|}
\hline $\begin{array}{l}\text { Case } \\
\mathbf{S}\end{array}$ & $\begin{array}{l}\text { Maximum } \\
\text { Deflection } \\
\mathbf{( m )}\end{array}$ & $\begin{array}{l}\text { Maximum } \\
\text { Rotation } \\
\text { (radians) }\end{array}$ & $\begin{array}{l}\text { Maximum } \\
\text { Bending } \\
\text { moment } \\
\mathbf{( K N m )}\end{array}$ & $\begin{array}{l}\text { Maximum } \\
\text { Shear force } \\
\mathbf{( K N )}\end{array}$ \\
\hline $\mathbf{1}$ & $9.6639 * 10^{-4}$ & $\begin{array}{c}- \\
3.29878 \\
10^{-9}\end{array}$ & 343.07309 & -1786.839 \\
\hline $\mathbf{2}$ & $2.42605 * 10^{-4}$ & $2.42605 * 10^{-4}$ & 86.121583 & -448.5499 \\
\hline $\mathbf{3}$ & $1.0769 * 10^{-4}$ & $1.0769 * 10^{-4}$ & 38.22895 & -199.1091 \\
\hline $\mathbf{4}$ & $6.07138 * 10^{-5}$ & $6.07138 * 10^{-5}$ & 21.552591 & -112.2531 \\
\hline
\end{tabular}

\subsection{Deflection:}

From the graphs shown in Figure 2, it was observed that the maximum deflection for the S-S short cylindrical shell occurs at the $1 / 2$ of the height $\mathrm{L}$ from the base.

The behavior of the graph showed that as the aspect ratio increases, from 1 to 4 , the deflection decreased.

\subsection{Rotation:}

From the graphs shown in Figure 3, it was observed that the maximum slope (rotation) for the $\mathrm{S}-\mathrm{S}$ short cylindrical shell occurs at the base. That is at $\mathrm{L}=0$. The behavior of the graph showed that as the aspect ratio increases from 1 to 4 , the rotation decreased.

\subsection{Bending Moment:}

From the graphs shown in Figure 4, it was observed that the maximum bending moment occurred at the $2 / 5$ of the height $\mathrm{L}$, from the base. That is at $\mathrm{L}=4 \mathrm{~m}$. The behavior of the graph showed that as the aspect ratio increased from 1 to 4 , the bending moment decreases.

\subsection{Shear Force:}

From the graphs of Figure 5, it was observed that the shear force varied along the height of the shell with the maximum values at the clamped base of the shell. The behavior of the graph showed that as the aspect ratio increases from 1 to 4 , the shear force decreased.

It was observed that as the aspect ratio increases from 1 to 4 , in all cases considered, the magnitudes of the deflections, rotations, bending moments and shears forces decreased and thus the short cylindrical shell tends to behave like long shell as shown in Tables 1 .

\section{CONCLUSION}

Using the polynomial series in the Conservation of work principle is convenient for analyzing S-S short cylindrical shells under axisymmetrical internal hydrostatic pressure. Design of such structure is made easier since the knowledge of the point of maximum stresses along the height of the shell is made possible through this analysis. This help for adequate reinforcement to be provided at the appropriate locations for a more safe, efficient and economic design. In the case of stiffening the shell with rings, this guides in the position of the rings for optimal design.

It is therefore recommended that this approach could be easily applied in solving S-S short cylindrical shell problems during the design of large cylindrical shell water reservoir.

\section{REFERENCES}

[1]. Vlasov V.Z. (1949). "A General Theory of Shells". Mir Publishers, Moscow

[2]. Timoshenko S.P. and Woinowsky-Krieger S. (1959). Theory of Plates and Shells, (2nd Ed). McGRAWHILL, New York. 
[3]. Pasternak P. L. (1932). "Practical Calculations for Folds and Cylindrical Shells Taking Bending Moments into Account". Stroitelnybyulleten, 9, 10.

[4]. Yukun, L., Wenhong, S.,Guan, D and Junhui, L (2013), "Stress calculation for large storage oil shell tanks".Advanced Materials Research, Vols, 602-604. Pp 2163-2169.

[5]. Osadebe. N.N. and Adamou.A (2010). "Static Analysis of Circular Cylindrical shell under hydrostatic and Ring forces". Journal of Science and Technology, vol. 30, No 1.Pp 141-150

[6]. Ventsel. E. and Krauthammer, T. (2001). "Thin plates and shell". New York, Marcel Dekker.

[7]. Ezeh, J.C, Ibearugbulem, O.M, Agbo, S. I and Maduh, U. J. (2014), "Static Analysis of C-S Short cylindrical shells under internal liquid pressure using polynomial series shape function" International Journal of Research in Engineering and Technology Vol. 3, Issue 02, Pp 474 - 479.

[8]. Ugural, A. C (1999). "Stresses in Plates and Shell". New York: McGraw-Hill.

[9]. Ibearugbulem, O. M, Ettu, L. O. and Ezeh, J. C. (2013), "Direct integration and Work principle as new approach in bending analysis of isotropic rectangular plates" The international journal of engineering and science. Vol. 2, Issue 3, Pp 28-36.

\section{BIOGRAPHIES}

[1]. Engr. Sylvester Ikechukwu Agbo is a lecturer in the department of Civil Engineering Federal University of Technology Owerri Imo State, Nigeria. He has a master's degree in structural Engineering.

[2]. Engr. Prof. B. U. Dike is currently the Head of Department of Civil Engineering, Federal University of Technology Owerri, Imo State, Nigeria. A professor of water resources and environmental engineering.

[3]. Engr. Timothy $U$ Anyanwu is a lecturer in the department of Civil Engineering Federal University of Technology Owerri Imo State, Nigeria. He has a master's degree in structural Engineering.

[4]. Engr. Ignatius C. Onyechere Agbo is a lecturer in the department of Civil Engineering Federal University of Technology Owerri Imo State, Nigeria. He has a master's degree in structural Engineering. 